\title{
APOSTILLAS DE HIDRONIMIA ARÁBIGO-MURCIANA \\ (Al margen de los Materiales para el Estudio de la Toponimia Hispanoárabe: \\ Nómina Fluvial, de Elías Terés) (1)
}

Por

ROBERT POCKLINGTON

Quiero, a través de estas breves líneas, dejar testimonio de la admiración que siento por la obra del insigne arabista y toponimista Elías Terés, obra siempre caracterizada por un riguroso método científico y amplísima documentación, que ha sido tristemente interrumpida por su muerte en el momento en que producía sus mejores frutos.

Sin duda lo que distingue al maestro en cualquier campo de estudios es el hecho de haber creado la base, el punto de partida, para todo trabajo posterior. Desde esta perspectiva desearía, mediante las presentes Apostillas, aportar a la obra hidronímica de nuestro maestro Elías Terés algunos nuevos datos y sugerencias referentes al área murciana.

\section{(A) Documentación de nuevos hidrónimos}

\section{BURTUY}

'Río Portús'

$$
\text { والدي برتبر }
$$

Río mencionado por el poeta árabe murciano Al-Qarțāŷannī (1211-1285) en el verso 432 de su Qașída Maqșüra (2). Según se desprende del contexto del poema, (el cual describe los movimientos de las nubes y la caída de la

(1) C.S.I.C., Instituto de Filología, Dept. de Estudios Árabes, tomo 1, Madrid, 1986, 519 págs.

(2) Qașắid wa-Muqațtāāât Șancat Abī-l-Hasan Hāzim Al-Qarțâyannī, edición del Dr. M. Ibn Al-Jūŷa, Al-Dār Al-Tūnisiyya li-l-Našr, Túnez, 1972, pág. 41; y Kitāb Rafo Al-Huŷub Al-Mastüra fi Mahāsin Al-Maqșüra, edición comentada por Abū-l-Qāsim Muhammad b. Ahmad (conocido como Al-Sarîf Al-Garnāțī), El Cairo, 1925 (1344 h.), vol. I, pág. 168. 
Iluvia en el campo de Cartagena, lugar en que el poeta nació y pasó su juventud), se trata de la actual Rambla de El Portús, que desemboca en el Mediterráneo ocho kilómetros al oeste del puerto de Cartagena (3).

El topónimo debe de remontar al latín Pertusium "perforación, paso», nombre que haría alusión al desfiladero por el que pasa el Wādi Burtuŷ, comunicando el Campo de Cartagena con el mar a través de la abrupta sierra costera. La dicha raíz latina daría en mozárabe *Pertúğ(o), que se transformaría sin dificultad en *Purtúğ en el hispano-árabe, dada su documentada tendencia a asimilar las vocales átonas a las tónicas (4); (la grafía árabe Burtuŷ puede representar una pronunciación Purtuŷ con P; el dialecto hispano-árabe sabía pronunciar el sonido $/ \mathrm{p} /$ en nombres $\mathrm{y}$ voces de procedencia no-árabe pero lo solía confundir con la $b$ en los textos escritos) (5).

Después de la Reconquista el nombre se conservó, asimilándose parcialmente al vocablo catalán (6) pertús uhoradado, perforado", del mismo origen latino. Así, en la documentación del s.XV encontramos con frecuencia la forma El Pertux (7). Posteriormente, el olvido del catalán en estas tierras hizo que el nombre, ya incomprensible, se transformara por etimologla popular en El Portús. (8).

En su estudio de la Qașida Maqșūra, E. García Gómez transcribió este topónimo "Bani Burtuŷ" en lugar de "Wãdi Burtuŷ", y propuso identificarlo con la acequia murciana de Benipotrós (9). Debe de tratarse de un error porque en ambas ediciones de la casida se lee claramente Wãdĩ y no Banīi además el contexto demuestra que era un paraje de los alrededores de Cartagena, muy distante de la Huerta de Murcia.

No obstante, es posible que exista una relación entre los dos topónimos. La documentación más antigua que conozco del nombre de la acequia es «Benipotrox" (1391) (10). De encontrarse este topónimo en un paraje montuoso se podría pensar en la etimología *Pennam Pertusii «Peña del Desfiladero»,

13) Para una traducción del pasaje en cuestión, junto con un intento de identificar algunos de los muchos topónimos citados por el poeta, ver: R. Pocklington, "Toponimia islámica del Campo de Cartagena", Historia de Cartagena, Ediciones Mediterráneo, Murcia, vol. V, 1986 (ed. 1987), 321-340, esp. pág. 334.

(4) Ver F. Corriente, A Grammatical Sketch of the Spanish Arabic Dialect Bundle, Instituto Hispano-Arabe de Cultura, Madrid, 1977, pág. 69; p. ej. en el Vocabulista de P. तa Alcalá: bollóta "bellotan, borrúca "verruga», pocóta "empicotar», xuntúra "cintura»...

(5) Exceptuando, claro está, los textos aljamiados, los cuales solian representar la /p/ con la letra b con tašdīo, como es bien sabido.

(6) La toponimia de la costa cartagenera sufríb una profunda influencia catalana durante la Baja Edad Media; ver A. Grandal, «Historia lingǘstica de Cartagena durante la Edad Media», Historia de Cartagena, Ediciones Mediterráneo, Murcia, 1986 (ed. 1988), 407-420.

(7) For ejemplo, en una Acta Capituiar del Concejo de Murcia, de 7-11-1477, se lee: "...en las pesquerías del Asuya e El Gorguer e en El Pertux e en Pormán", donde se trata de los lugares costeros hoy llamados La Azohía, El Gorguel, El Portús y Portmán respectivamente.

(8) Es posibie que el cambio se produjera ya en el catalán, puesto que la alternación Pertús-Portús también se da en la toponimia catalana; ver E. Moreu-Rey, Els Nostres Noms de Lloc, Editorial Moll, Mallorca, $1982,38$.

(9) E. García Gómez, "Observaciones sobre la 'Qașida Maqșūra' de Abū-l-Hasan Hāzim Al-Qarțāyannī", AlAndalus, I, 1933, 81-103, esp. págs. 94 y 101.

(10) J. Torres Fontes, Los Baños de la Reina, Academia Alfonso X el Sabio, Murcia, 1975, pág. 14. 
con la conversión de Penna en Beni por etimología popular (71). Pero hallándose Benipotrós en medio de la llanura, apenas puede caber duda de que sea un antropónimo árabe en Bení, derivado de un nombre de linaje de procedencia mozárabe Portox, que a su vez bien podría tener un origen toponímico relacionado con algún lugar llamado Pertusium / Pertúš, de los muchos que han existido en la Península (12). Es probable que el Aben Portos que, hacia el año 1265, era "alcalde y señor de Écija» (13), pertenecía al mismo linaje.

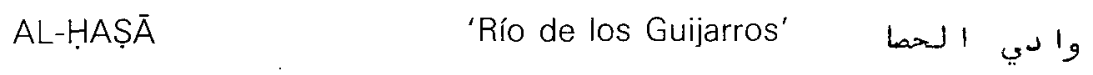

Nombre de un río de los alrededores de la ciudad de Cartagena, citado, como el anterior, por Al-Qarțāŷannĩ en la Qașīda Maqșūra, verso 398 (14). Es uno de una larga lista de topónimos, todos los cuales quizás podrían ser identificados, con la ayuda de la siguiente descripción, por un buen conocedor de aquellos parajes:

"Y las nubes fueron generosas con $R a^{\prime} s$ Al-c $A y n$ (la Cabeza de la Fuente) y Al-Marŷ (el Prado), dando riego al campo cuando descendieron.

Vertiendo su agua sobre Al-Diyāc (las Aldeas) y sobre Al-Șafã (la Piedra), que rodea Al-Mustaqā (el Abrevadero).

Y Al-Saraf Al-Aclà (el Mirador Alto) que da vistas sobre él, hasta donde se derraman las aguas en WĀDT AL-HAȘĀ.

Y los planteles de abrótano, desde el fondo del lecho del río, hasta los más apartados de los árboles circundantes.

Y luego a la bajada del torrente, y las plantaciones que están en Al-Ramla (la Rambla), enrojecida por los depósitos de arenas...".

(Qașida Maqșüra, versos 396-400) (15).

Este hidrónimo no reaparece en ningún otro texto, ni se conservó después de la Reconquista. La voz hașā «guijarros» es rara en la toponimia hispánica; no conozco otras instancias de su uso aparte de las formas Alhuçeya y Alhaçayt documentadas por J. Martínez Ruiz en Cúllar-Baza en el año 1492 (16), que podrían corresponder respectivamente al diminutivo Al-Hușayya, y al plural: Al-Hașayāt (o acaso el diminutivo plural Al-Huṣayyāt), con la terminación -āt pronunciada /-it/ de bido a la intensa imela característica del árabe granadino tardío.

(11) Ver: M. J. Rubiera y M. de Epalza, Los Nombres Árabes de Benidorm y su Comarca, Ayuntamiento de Benidorm / Universidad de Alicante, 1985, 16-20.

(12) Ver E. Moreu-Rey, loc. cit. En Setúbal (Portugal). existe un orónimo Alpertuche, que seguramente tiene el mismo origen (M. Terrón Albarrán, El Solar de los Aftásidas, Centro de Estudios Extremeños, Badajoz, 1971, 668).

(13) Ver: J. González, Repartimiento de Sevilla, C.S.I.C., Madrid, 1951, I, 60.

(14) Ver las ediciones citadas en la nota 1, págs. 39 y 161 respectivamente.

(15) Para una versión más completa de esta sección de la casida ver: R. Pocklington, "Toponimia islámica...", op. cit., págs. 327-335.

(16) J. Martínez Ruiz, "Algunos topónimos menores de Cúllar-Baza (Granada), en el año 1492", Homenaje a E. Palacios, M. Vallecillo y M. Pérez, Universidad de Granada, 1985, 131-145 (pág. 136). No me parece satisfactoria la propuesta derivación de Alhaçayt de la forma verbal hasayt «abundo en piedras" (más exacto sería "abundé/ abundaste en piedras»), cuyo significado resulta inapropiado, tratándose de un nombre de lugar 


\title{
(B) Observaciones sobre un hidrónimo conocido
}

\author{
MUNŶU'S
}

'Río Mundo'

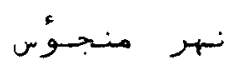

La identificación del «Nahr Munŷu's» con el Río Mundo (17) no parece dejar lugar a dudas, dada la claridad de la descripción de Al-Zuhrī, único geógrafo hispanoárabe que recoge este hidrónimo. Sin embargo, desde el punto de vista de la lingüística, la derivación del nombre actual Mundo de la forma arabizada Munyu's tropieza con grandes dificultades a causa de la imposibilidad de explicar de manera satisfactoria la conversión del sonido $/ \hat{y} /$ en $/ \mathrm{d} /$. Además, la grafía Munŷu's seguramente ha sufrido alguna deformación, ya que no corresponde a nunguna raíz árabe, ni puede ser un nombre autóctono porque la presencia de la hamza (') no se explicaría.

Si examinamos la serie de variantes que ofrecen los diferentes manuscritos de Al-Zuhrī (18), observamos que Munŷu's no es, ni mucho menos, la más característica:

Manuscrito de Paris:

Manuscrito de Rabat:

$M-n-\hat{y} u^{\prime}-s$

Manuscrito de Londres:

$M-n-\hat{y}-r-\breve{s}$

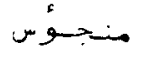

Manuscrito de Madrid:

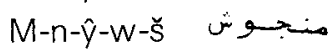

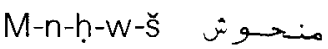

La adopción, ya habitual, de la forma Munŷu's supone la aceptación de la variante del ms. de París (M-n-ŷy'-s), y la elección de una vocalización con /u/ y sukūn (Munŷu's), pasos cuya principal justificación parece residir en un pretendido acercamiento de la forma árabe al nombre actual del río Mundo.

No obstante, las cuatro variantes recogidas en los diferentes manuscritos se prestan a diversas interpretaciones. Sin ir más lejos, el propio editor de Al-Zuhrī lee "Mandja'us» (Manŷa'us), proponiendo su identificación con el río Manzanares (19), en lo que evidentemente se equivoca.

Si contemplamos de nuevo las cuatro variantes, observamos que todas contienen cinco signos consonánticos. El primero es siempre $\mathrm{M}$, y el segundo $N$. El tercero es $\hat{Y}$ en todos los manuscritos excepto el de Madrid, el cual tiene $H$; evidentemente la mejor lectura es $\hat{Y}$, donde la $H$ del texto madrileño se deberá a la pérdida de un punto diacrítico. El cuarto signo es: $W$ en los manuscritos de Londres y Madrid, $W$ con hamza en el de París, y $R$ en el de Rabat; la lectura W se impone por encontrarse en tres de los cuatro manuscritos; la hamza del texto parisino debe de ser un error de copia, ya que difícilmente se habría introducido este sonido en un topónimo de origen romance; la $R$ de la versión magrebí también puede explicarse como un error de transmisión, dada la facilidad con la que se confundían las grafemas $W$ y $R$ en algunos manuscritos. La última letra es $\breve{S}$ en todas las variantes excepto la

(17) E. Terés, Op. cit., pág. 128

(18) "Kităb al-Dja`rāfiyya. Mappemonde du calife al-Ma'mūn...», edición y estudio de M. Hadj-Sadok, Bulletin d'Etudes Orientales, XXI, 1968, Damasco, pág. 208, párr. 256.

(19) Op. cit., pág. 143. 
parisina, la cual tiene $S$, probablemente por error de un amanuense que olvidó añadir los tres puntos diacríticos.

De todo ello se desprende que la variante más representativa es la del manuscrito Iondinense: $M-n-\hat{y}-w-\breve{s}$. Habiendo llegado a este punto, la clave para la correcta interpretación del hidrónimo puede estar en el hecho, ya puesto de relieve por distintos autores, de que, según el mismo Al-Zuhrī, el tramo alto del río Mundo se llamaba Nahr Mayšuniš (20) «Río de Mesones» (el río pasa cerca del pueblo de este nombre). Ahora, la etimología latina de Mayšu niš - Mesones es sin duda: Mansiones "Las Posadas», vocablo que entraría en el mozárabe como *Mayzones, y cuya sibilante sonora algo palatalizada (z), pronunciable en el hispanoárabe pero careciendo de correspondencia exacta en el árabe clásico, hubo de transcribirse ora con $\hat{S}$, ora con $\hat{Y}(21)$; (en los documentos toledanos publicados por A. González Palencia hallamos las dos grafías: al lado del singular mayšūn «mesón» con (š), está el plural mayā yin "mesones" con $(\hat{Y})(22)$.

En vista de estos hechos queda claro que el nombre mozárabe del pueblo de Mesones pudo escribirse en árabe tanto Mayšuniš como Mayŷūniš, y no creo que el topónimo $M-n-\hat{y}-w-\breve{s}$, que nos hemos acostumbrado a decir "munŷu's», sea otra cosa que una deformación gráfica de Mayyuaniš. Al confrontar las respectivas grafías árabes, salta a la vista que las diferencias entre elias son de muy escasa importancia, sobre todo teniendo en cuenta que ambos nombres se aplicaban al mismo río:

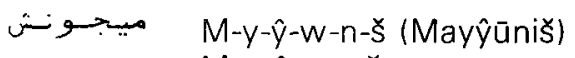

$$
\begin{aligned}
& \text { م من } M-n-\hat{y}-w--\grave{s}
\end{aligned}
$$

Las diferencias se reducen a dos y tienen sencillas explicaciones: (A) el cambio $(y)>(n)$ se produciría por una incorrecta colocación de los puntos diacríticos; y (B) la desaparición de la penúltima consonante (n) es atribuible a la confusión de su trazo vertical y punto diacrítico con los tres trazos verticales y tres puntos diacríticos de la ( $(\zeta)$ final.

Como conclusión, convendría corregir la entrada MīSŪNĪ̌s (página 126), poniendo en su lugar MAYSUNIS, y suprimir la entrada MUNŶYU'S (página 128), incorporando sus datos al artículo MAYSUNIS.

(20) No Mišuniš. El nombre viene sin vocalizar en Al-Zuhrī, de modo que podemos leer tanto Mayšüniš como Misuanis. Veremos más abajo que, por motivos etimológicos y otros, la grafía Maysuñis es la más adecuada.

121) Los biógrafos estaban conscientes de esta dificultad. Por ejemplo, Ibn Ai-Abbār, en su $M u^{c} \hat{y} a m$ fi

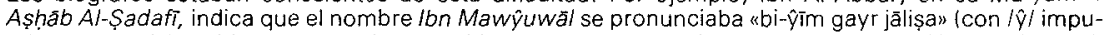

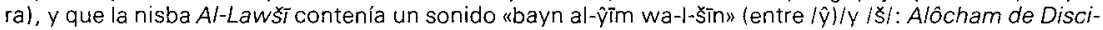
pulis Abu Ali Assadafi, ed. F. Codera, Bibliotheca Arábico-Hispana, IV. Madrid, 1886, biografías 207 y 290.

(22) Ver J. Corominas y J. A. Pascual, Diccionario Critico Etimológico Castellano e Hispánico, Gredos, Madrid, 1980 ss., s. v. MANIDO, nota 2. La misma vacilación gráfica se detecta en otros topónimos que contenían ese sonido. Por ejemplo, el nombre de la ciudad jiennense de Quesada se escribía tanto Qayšăța como Qayȳâța en las fuentes árabes; y los lugares valencianos llamados 'Aqabat Abiša y Anǐsa con (Š) según unos autores, eran 'Aqabat Abîya y Anî̀a con $(\hat{y})$ según otros (ver E. Terés, "Al-cAqaba. Notas de toponimia hispanoáraben, Al-Andalus, XLIII, 1978, 369-403, esp. págs. 375-7). 